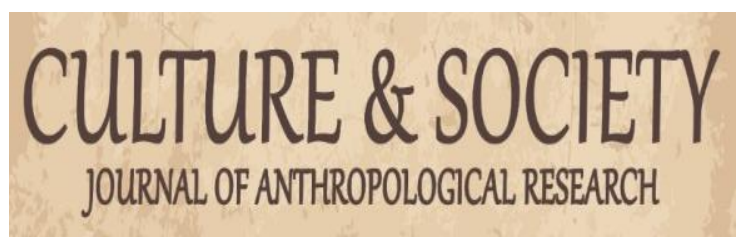

Culture \& Society: Journal of Anthropological Research

VOL. 1 NO. 1 SEPTEMBER 2019

http://culture.ppj.unp.ac.id

Email: culture@ppj.unp.ac.id

ISSN: 2686-343X (E-ISSN) 2686-3421 (P-ISSN)

DOI: https://doi.org/10.24036/culture/vol1-iss1/9

\title{
Nilai-Nilai Solidaritas Sosial dalam Komunitas Penari Lintas Community (PLC) Kota Payakumbuh
}

\author{
Ririn Alwani ${ }^{1}$, Erianjoni Erianjoni ${ }^{2}$ \\ ${ }^{1,2}$ Universitas Negeri Padang \\ Email: ririnalwanii@gmail.com, erianjonisosiologi@gmail.com
}

\begin{abstract}
Abstrak
Penelitian ini membahas tentang nilai-nilai solidaritas sosial dalam komunitas Penari Lintas Community (PLC) Kota Payakumbuh. Tujuan penelitian ini adalah untuk menjelaskan dan mengungkap nilai-nilai solidaritas sosial dalam komunitas Penari Lintas Community (PLC) Kota Payakumbuh.Penelitian ini dianalisis dengan menggunakan teori Emile Durkheim tentang solidaritas sosial. Menurut Durkheim solidaritas terbagi menjadi dua yaitu solidaritas mekanis dan solidaritas organis. Penelitian ini merupakan penelitian kualitatif dengan tipe penelitian kasus intrinsik yaitu studi kasus. Pengumpulan data dilakukan dengan cara observasi, wawancara dan studi dokumentasi. Informan penelitian berjumlah 22 orang yang terdiri atas anggota PLC dan pemilik warung yang dijadikan sebagai Basecamp. Teknik pemilihan informan dilakukan dengan teknik purposive sampling. Validitas data menggunakan teknik triangulasi data. Teknik analisis data dari Miles dan Huberman (reduksi data, penyajian data dan penarikan kesimpulan). Dalam penelitian ini terdapat tiga nilai solidaritas sosial yang dimiliki PLC yaitu nilai kekeluargaan, saling membantu dan menolong serta musyawarah.
\end{abstract}

Kata Kunci: Nilai-Nilai, Solidaritas Sosial, Komunitas, Penari Lintas Community

\section{Abstract}

This research discusses the values of social solidarity in the Payakumbuh City Cross Community Dancer (PLC) community. The purpose of this study was to explain and reveal the values of social solidarity in the Payakumbuh City Cross Community (PLC) Dancer community. This study was analyzed using Emile Durkheim's theory of social solidarity. According to Durkheim solidarity is divided into two, namely mechanical solidarity and organic solidarity. This study is a qualitative study with an intrinsic case research type, which is a case study. Data collection is done by observation, interview and documentation study. The research informants were 22 people consisting of PLC members and stall owners who were used as Basecamp. The informant selection technique was carried out by purposive sampling technique. Data validity uses data triangulation techniques. Data analysis techniques from Miles and Huberman (data reduction, data presentation and conclusions). In this study there are three values of PLC social solidarity which are family values, mutual help and help and deliberation.

Keywords: Values, Social Solidarity, Community, Cross Community Dancers

\begin{tabular}{l|l|l} 
Received: August 29, 2019 & Revised: September 4, 2019 & Published: September 5, 2019 \\
\hline
\end{tabular}




\section{Pendahuluan}

Di dalam keseharian dapat di lihat setiap orang membentuk kelompok. Kelompok sosial atau himpunan manusia tidak dapat dikatakan sebagai kelompok social seluruhnya (Dilema, 2017) . Contohnya kelompok orang yang berada di terminal, berada di sekolah, berada di kampus, berada di kantor, dandi tempat-tempat umum lainnya. Kelompok-kelompok tersebut ada yang bersifat formal maupun non-formal, diantara semua kelompok tersebut mereka akan membentuk suatu hubungan timbal balik antara satu dengan lainnya yang disebut interaksi. Aktivitas social adalah factor utama yang membentuk proses umum interaksi social. Hubungan yang bersifat dinamis dan berkaitan dengan hubungan antara individu dengan individu, kelompok dengan kelompok, ataupun individu dengan kelompok manusia merupakan bentuk lain dari proses sosial yang merupakan bentuk-bentuk khusus dari interaksi sosial (Soekanto Soerjono, 1982).

Kelompok sosial yang kini disebut dengan komunitas merupakan suatu unit atau kesatuan sosial yang terorganisasikan dalam kelompok-kelompok dengan kepentingan bersama (communities of common interest), baik yang bersifat fungsional maupun yang mempunyai territorial (Siwi Mahmudi, n.d.). Komunitas terbentuk oleh berbagai tujuan, pandangan dan pemahaman tentang pengetahuan menciptakan proses. Berbagi pengalaman menciptakan keyakinan mendalam dan aturan dasar tentang menjadi anggota sebuah komunitas (Abdullah, 2013).

Masyarakat heterogen adalah masyarakat yang satukan oleh satu sistem kekeluargaan, sistem budaya, dan system adat yang sama, masayarakat seperti inilah yang umum ada di dalam komunitas (Utami \& Silalahi, 2013). Berkumpul serta bergerak dalam aksi bersama, dalam agenda rutinitas komunitas ataupun agenda kegiatan event-event, misalnya peringatan hari Nasional dan undangan dari macam-macam kegiatan perayaan yang mendukung kegiatan dalam komunitas dan lainnya yang tentu saja kegiatan tersebut merujuk pada sistem solidaritas sosial komunitas terhadap sesama anggotanya. Hal tersebut adalah hal yang masih dipertahankan oleh masyarakat dalam komunitas.

PLC (Penari Lintas Community) kota Payakumbuh merupakan wadah komunitas semua jenis kendaraan pengguna jalan raya lintas Sumatera Barat-Riau seperti kendaraan pribadi baik sepeda motor maupun mobil, pick up, truck dan bus. Komunitas ini beranggotakan dari semua kalangan dan berbagai latar belakang budaya, profesi, dan daerah. Penari Lintas Community adalah salah satu komunitas bergengsi di lintasan Sumbar-Riau. Karena PLC sendiri termasuk salah satu komunitas pelopor keselamatan berkendara di jalan. Menjalin silaturahmi antar sesama pengguna jalan dan menciptakan rasa kekeluargaan. Saat ini anggota komunitas ini yang biasa mereka sebut member berjumlah kurang lebih 1600 yang aktif dari jumlah sebelumnya yaitu kurang lebih 18.000. PLC di perketat karena sudah berbadan hukum, sehingga member komunitas didata ulang agar lebih terorganisir dengan baik. Jumlah anggota yang banyak dan kehidupan yang keras dijalanan membuat anggota komunitas harus memiliki nilai-nilai solidaritas sesama anggota dalam komunitas tersebut.

Komunitas PLC ini tidak memiliki badan struktur organisasi, karena para pendiri PLC tidak ingin ada yang dipimpin dan memimpin. Bagi mereka semua member PLC sama semua saudara. Untuk mempermudah jalannya kegiatan dan rutinitas serta segala hal komunitas ini hanya menunjuk satu orang admin untuk setiap regional.

PLC (Penari Lintas Community) awalnya bernama TMC (Travel Mania Community) adalah sebuah forum diskusi dan silaturrahmi rekan-rekan Travel Sumbar-Riau melalui Facebook yang membahas seputar lintasan travel antara Sumbar-Riau yang dibentuk tahun 2015. Pada awalnya TMC hanya fokus sebagai wadah menyatukan rekan-rekan travel resmi-non resmi dan bensin-solar, dan hal-hal lain yang berhubungan dengan lintasan travel khususnya Sumbar-Riau. Tetaapi seiring berjalannya waktu TMC berganti nama menjadi PLC dan tidak lagi terbatas pada jenis angkutan travel saja. PLC dijadikan tempat untuk saling berinteraksi, berkomunikasi dan ajang silahturahmi di kehidupan sehari-hari oleh sesama pengguna lintasan. Rasa nyaman dan saling membutuhkan membuat anggota PLC membentuk Whatsapp Group (WA) berdasarkan wilayah domisili masing masing. Lewat Whatsapp Group ini member PLC bisa koordinasi untuk

\section{Culture \& Society: Journal of Anthropological Research Vol. 1, No. 1, Th. 2019}


kopdar, silahturahmi, saling membantu dan melakukan kegiatan sosial. Sebagai identitas PLC punya sticker Logo PLC nasional (depan) yang telah disepakati bersama, dan logo PLC tiap tiap daerah/ wilayah juga punya identitas berupa sticker wilayah yang didesain sendiri oleh masing masing wilayah.

Sebuah komunitas tidak luput dari rasa atau ikatan dari hati yang tumbuh secara alami. Sesama anggota memiliki rasa solidaritas yang tinggi (Rolitia, Achdiani, \& Eridiana, 2016). Bahkan rasa solidaritas ini meluas bukan hanya sesama anggota komunitas Penari Lintas Community (PLC) kota Payakumbuh saja, namun dengan komunitas Penari Lintas Community di daerah lainnya. Mereka menganggap semua Komunitas Penari Lintas Community adalah keluarga. Tercermin dari pertemuan mereka yang intens, duka cita yang dirasakan bersama, bahkan sampai menampung anggota komunitas lain yang butuh tumpangan untuk menginap, dan banyak lagi lainnya. Penari Lintas Community sendiri memiliki beberapa moto khusus diantaranya "Bebas beretika", "Saudara ga mesti sedarah", "Lebih dari teman kami adalah keluarga", "Dima singgah disitu ado dunsanak, "Elo Gue Kita", "Brotherhoods Forever, dan masih banyak lagi.

Penelitian ini berkaitan dengan penelitian yang dilakukan oleh Febrian Dicky Setiawan tentang Solidaritas Sosial Anggota Komunitas Motor Honda Classic Magelang (HCM) "Cub Series" (Dicky, 2016). Penelitian berikutnya Is Durotus Sa'diyah tentang Solidaritas Sosial Masyarakat Kuningan di Yogyakarta (Studi Kasus: Komunitas Paguyuban Pengusaha Warga Kuningan (Iis Durotus, 2016). Penelitian berikutnya oleh Tessi Septiani tentang Internalisasi Nilai-nilai Sosial dalam Komunitas Pecinta Alam Aru-Aru Minang Adventure (KPAAMA) di Nagari Kasang Kecamatan Batang Anai Kabupaten Padang Pariaman (Septiani Tessi, 2017).

Penelitian mengenai nilai-nilai solidaritas sosial anggota Penari Lintas Community (PLC) Kota Payakumbuh ini dianalisis menggunakan Teori Solidaritas Sosial yang dikemukakan oleh Emile Durkheim. Durkheim sangat tertarik dengan perubahan cara di mana solidaritas sosial terbentuk, dengan kata lain perubahan cara-cara masyarakat bertahan dan bagaimana anggotanya melihat diri mereka sebagai bagian yang utuh. Menurut Durkeim solidaritas sosial terbagi menjadi dua yaitu solidaritas mekanis dan solidaritas organis. Solidaritas mekanis adalah solidaritas yang dibentuk dari hukum represif karena anggota masyarakat tersebut memiliki persamaan dan sangat cenderung percaya kepada moralitas bersama. Setiap pelanggaran pada sistem bersama tidak dianggap main-main oleh setiap individu. Bagi yang melanggar moral kolektif maka akan dihukum. Walau hanya merupakan pelanggaran kecil tetapi bisa saja akan di hukum berat. Sedangkan solidaritas organis dibentuk oleh hukum restitutif. Yaitu ketika pelanggar harus melakukan restitusi untuk pelanggarannya. Bagi mereka pelanggaran merupakan serangan terhadap individu atau sekmen tertentu dari masyarakat bukan terhadap sistem moral itu sendiri. Kurangnya moral mereka tidak membuat mereka melakukan reaksi emosional terhadap pelanggaran hukum.

Penelitian ini bertujuan untuk menjelaskan dan mengungkap nilai-nilai solidaritas sosial anggota Penari Lintas Community Kota Payakumbuh. Penulis berharap artikel ini dapat menjadi tambahan untuk mengembangkan teori sosiologi perkotaan mengenai nilai-nilai solidaritas sosial anggota Penari Lintas Community dan dapat menjadi suatu tambahan bacaaan bagi pihak-pihak yang ingin membaca mengenai nilai-nilai solidaritas sosial anggota Penari Lintas Community.

\section{Metode Penelitian}

Pendekatan dalam penelitian ini menggunakan pendekatan kualitatif. Pendekatan kualitatif ini bertujuan menggali atau menjelaskan makna dibalik realita. Penelitian berpijak dari realita atau peristiwa yang berlangsung di Lapangan (Bungin, 2001). Tipe penelitian yang digunakan adalah penelitian kasus intrinsik yaitu studi kasus yang dikenal sebagai studi yang bersifat komprehensif, intens, rinci, dan mendalam serta lebih diarahkan pada upaya menelaah masalah atau fenomena kontemporer yang bersifat kekinian (Bungin, 2003). Studi kasus bertujuan untuk mempertahankan keutuhan objek, yang artinya data yang terkumpul dipelajari sebagai suatu keseluruhan yang terintegrasi, studi kasus intrinsik dilakukan untuk memahami secara utuh suatu kasus tanpa harus

\section{Culture \& Society: Journal of Anthropological Research Vol. 1, No. 1, Th. 2019}


menghasilkan konsep atau teori. Penelitian kualitatif dipilih karena dipandang mampu menemukan defenisi serta gejala sosial dari subjek. Penelitian ini dilakukan di Kota Payakumbuh, khususnya ditempat yang sudah ditentukan bersama-sama oleh anggota komunitas dan mereka sebut basecamp. Basecamp Penari Lintas Community Kota Payakumbuh berada di bypass, subarang batuang.

Pemilihan informan dilakukan secara purposive sampling (sampel bertujuan) untuk mendapatkan keterangan dan data yang relevan dengan tujuan (Maleong, 1998). Purposive sampling yaitu informan ditentukan dengan sengaja oleh peneliti atau tidak secara acak, artinya informan dalam penelitian ini ditentukan oleh peneliti sesuai dengan maksud dan tujuan penelitian. Untuk mendapatkan data sesuai dengan tujuan, maka penulis menggunakan kriteria dalam pemilihan informan penelitian ini. Kriteria tersebut adalah: Admin Komunitas di Penari Lintas Community Kota Payakumbuh, pemilik warung yang dijadikan sebagai basecamp tempat berkumpulnya anggota Penari Lintas Community (PLC), dan 21 (dua puluh satu) angota Penari Lintas Community lainnya.

Observasi yang dipakai adalah observasi partisipan yang merupakan kegiatan keseharian manusia dengan menggunakan panca indera mata sebagai alat bantu utamanya selain dari panca indera seperti telinga, penciuman, mulut, dan kulit (Bungin, 2007). Observasi dilakukan dengan datang langsung ke basecamp Penari Lintas Community dan mengikuti beberapa kegiatan yang diadakan ole komunitas tersebut seperti kopdar mingguan. Hal tersebut bertujuan untuk menggambarkan setting yang dipelajari, serta aktivitas-aktivitas yang berlangsung, dan orangorang yang terlibat dalam kejadian yang diamati. Umumnya observasi partisipan bersifat openended, yaitu peneliti mengajukan pertanyaan-pertanyaan umum kepada partisipan yang dapat membuat partisipan bebas memberikan pandangan-pandangan mereka (W. John, 2010). Kemudian setelah melakukan observasi peneliti lanjut melakukan wawancara dengan subjek penelitian yaitu admin Penari Lintas Community, pemilik warung yang dijadikan basecamp, dan anggota Penari Lintas Community lainnya. Wawancara mendalam yaitu proses memperoleh keterangan untuk tujuan penelitian dengan cara tanya jawab sambil bertatap muka antara pewawancara dengan informan atau orang diwawancarai. Wawancara mendalam dapat dilakukan dengan menggunakan pedoman (guide) wawancara, sehingga wawancara menjadi terarah dan terstruktur. Wawancara mendalam ini biasanya dilakukan dimana pewawancara dan informan terlibat dalam kehidupan sosial yang relatif lama, sehingga kekhasan wawancara mendalam adalah keterlibatannya dalam kehidupan informan (Bungin, 2003). Untuk mendapatkan data yang valid dan dilakukan berkali-kali sesuai dengan keperluan maka wawancara dilakukan secara terbuka. Teknik triangulasi data dilakukan agar data yang peneliti peroleh dalam penelitian hasilnya lebih akurat, valid serta sah. Kemudian dalam Triangulasi data, data hasil wawancara, observasi dan dokumentasi harus dibandingkan. Jika data teknik-teknik pengumpulan data diatas menghasilkan data yang tidak sama, maka penulis harus melakukan diskusi lanjut terhadap informan yang bersangkutan agar mendapatkan data yang benar (Sugiyono, 2005). Teknik analisis data digunakan dengan teknik analisis data dari Miles dan Huberman yaitu reduksi data, penyajian data, dan penarikan kesimpulan.

\section{Hasil dan Pembahasan}

Penari Lintas Community berdiri dengan maksud dan tujuan sebagai berikut: Komunitas ini bertujuan untuk menghimpun dan mewadahi para pemilik, pengguna dan pecinta Moda Transportasi Darat di Indonesia untuk berkomunikasi, bersosialisasi dan berinteraksi secara positif. Membina, meningkatkan, mengembangkan hubungan silaturahmi para pemilik, pengguna dan pecinta otomotif. Turut menanamkan disiplin akan tertib lalu lintas kepada umum dan para anggotanya. Menyelenggarakan berbagai kegiatan antara lain: olahraga, sosial, wisata bagi anggotanya. Membangun Penari Lintas Community sebagai komunitas dengan rasa kebersamaan yang kuat, solidaritas yang tinggi dan bersifat kekeluargaan disertai kepengurusan yang

\section{Culture \& Society: Journal of Anthropological Research Vol. 1, No. 1, Th. 2019}


profesional. Menjadikan Penari Lintas Community sebagai adah tempat bersosialisasi, berbagi ilmu, informasi, pengalaman dan networking.

Selain itu Penari Lintas Community juga memiliki visi dan misi. Visi Penari Lintas Community yaitu, penari Lintas Community mempunyai visi untuk menjadikan sebuah komunitas yang turut serta memajukan dan membesarkan dunia otomotif Indonesia, sebagai komunitas otomotif yang sarat dengan benefit bagi para anggotanya serta penuh dengan kegiatan yang bersifat positif, sebagai komunitas pelopor berbagai program keselamatan dan kenyamanan berlalulintas, sebagai komunitas sosial yang bermanfaat bagi masyarakat sekitar.

Sedangkan misi Penari Lintas Community adalah mempersatukan para pemilik, pengguna dan pecinta Moda Transportasi Darat di seluruh Indonesia. Menjalin kerjasama mutualisme dengan berbagai pihak yang berhubungan dengan otomotif dan bidang pendukung lainnya sebagai manfaat serta benefit bagi seluruh anggota. Merancang dan melaksanakan berbagai program sosial dengan isu eksternal dan isu internal dalam menghadirkan solusi sebagai bentuk kontribusi terhadap masyarakat dan lingkungan.

Anggota PLC Kota Payakumbuh saat ini sudah terdiri dari anggota yang beragam jenis pekerjaan status dan budaya. Ada yang merupakan anggota kepolisian, supir ambulance RSUD, supir Bus Sekolah, Supir ekspedisi, dan lain sebagainya. Dalam waktu 3 bulan sekali PLC melakukan tinjauan keaktifan anggota. Serta PLC juga melakukan razia dijalanan, karena begitu banyak oknum yang telah menyalahgunakan sticker PLC. Dan dengan razia tersebut admin dan pengurus induk mulai mengetahui bahwa ternyata sticker PLC diperjualbelikan oleh oknum yang tidak bertanggung jawab dengan harga yang terbilang mahal yaitu $\mathrm{Rp} 100.000-\mathrm{Rp} 250.000$. Razia tersebut harus dilakukan karena jumlah anggota PLC yang begitu banyak dan banyak oknum yang tidak bertanggung jawab mengatasnamakan PLC. Oleh sebab itu nilai-nilai solidaritas sosial dalam kelompok PLC ini sangat dibutuhkan. Selama melakukan observasi dan wawancara peneliti menemukan ada tiga nilai-nilai solidaritas yang ditanamkan didalam anggota komunitas PLC yaitu, nilai kekeluargaan, saling membantu dan menolong serta musyawarah.

\section{Nilai Kekeluargaan}

Jika ada anggota komunitas yang sakit, meninggal, kecelakaan atau keluarga dari anggota ada yang sakit atau tertimpa musibah lainnya maka anggota lainnya akan turut bersedih atau berduka bahkan membantu meringankan beban anggota tersebut. Tidak hanya anggota PLC Kota Payakumbuh saja, bahkan bagi setiap anggota seluruh anggota PLC senusantara merupakan kelurga mereka. Berdasarkan penelitian yang dilakukan, peneliti menemukan bahwa tidak hanya antar anggota, terkadang komunitas ini juga mengadakan kopdar di rumah salah satu anggota yang sudah berkeluarga secara bergantian dan tentunya sudah disepakati bersama. Dan untuk menjaga keutuhan rumah tangga anggota dan juga untuk menghindari terjadi sesuatu yang tidak diinginkan maka mereka membuat WA group yang terpisah untuk anggota laki-laki dan anggota perempuan. WA group khusus anggota perempuan diberi nama Kartini PLC, tidak hanya anggota perempuan saja yang tergabung didalam WA group tersebut bahkan para isteri dari anggota lakilaki ikut tergabung di dalam WA group tersebut. selain melakukan kopdar mingguan di rumah salah satu anggota secara bergantian komunitas PLC juga pernah mengadakan acara tour ke Singkarak bersama keluarga yaitu anak dan isteri mereka bagi yang sudah menikah.

\section{Saling Membantu dan Menolong}

Hal inilah yang umum dilakukan oleh anggota PLC kota Payakumbuh. Jika ada anggota lainnya mengalami masalah atau tertimpa musibah maka mereka akan saling membantu. anggota PLC selalu bersedia membantu dan menolong anggota yang mengalami musibah kecelakaan lalu lintas dimanapun maupun musibah kerusakan mobil di jalan. Selain itu anggota PLC juga tidak segan-segan memberi tumpangan kepada anggota yang membutuhkan tumpangan bahkan masayarakat biasa yang tidak tergabung di dalam komunitas PLC ataupun anggota komunitas lain. Dari hasil penelitian penulis tidak hanya antar anggota saja, bahkan masyarakat biasa yang bukan merupakan anggota PLC juga akan tetap mereka bantu. Bahkan tidak sedikit anggota yang 
bergabung adalah pemilik kendaraan mobil pribadi yang tertarik bergabung setelah dibantu oleh anggota PLC. Bahkan komunitas PLC ini juga mendapatkan beberapa piagam kemanusiaan karena telah membantu mengadakan penggalangan dana untuk para korban bencana dibeberapa daerah. Salah satunya adalah piagam kemanusian bantuan untuk korban bencana di Lombok serta piagam kemanusiaan bantuan untuk korban bencana di Palu-Donggala. Komunitas Penari Lintas Community juga memiliki logo sticker yang bertuliskan "bagikan sesuatu yang baik, komunitas untuk manfaat" yang sangat sesuai dengan nilai-nilai solidaritas sosial saling membantu dan menolong ini. Jika dianalisis dengan teori Emile Durkheim tentang solidaritas sosial yang menekankan bahwa solidaritas organis adalah suatu sistem terpadu yang terdiri atas berbagai bagian yang saling terhubung seperti bagian-bagian suatu organ biologis (Ritzer, 2012). Dengan kata lain di dalam komunitas Penari Lintas Community seluruh anggota PLC saling tergantung dan saling membutuhkan bantuan dan pertolongan.

\section{Musyawarah}

Menurut hasil penelitian, di dalam komunitas PLC kota Payaumbuh keputusan bersama selalu diambil melalui musyawarah bersama. Di dalam musyawarah tersebut semua bebas berpendapat yang terpenting adalah tetap beretika. Ada beberapa hal yang harus diadakan musyawarah untuk mendapatkan keputusan bersama didalam komunitas PLC, diantaranya musyawarah untuk menentukan dana acara tertentu, musyawarah tentang konflik yang terjadi antar anggota, musyawarah untuk masalah yang terjadi seperti jika ada anggota yang bermasalah maka keputusan apa yang akan diambil, dan Munas (Musyawarah Nasional) untuk membentuk kepengurusan induk (moderator) yang baru dan masih banyak lagi. musyawarah adalah hal yang harus dilakukan disaat segala sesuatu memerlukan solusi atau jalan keluar. Admin tidak bisa menggunakan wewenangnya secara sebelah pihak untuk membuat segala keputusan, harus ada musyawarah atau diskusi bersama terlebih daulu agar keputusan bisa diterima bersama-sama tanpa ada konflik baru. Dan bagi yang melanggar aturan yang ada didalam komunitas maka akan diberi sanksi baik ringan maupun berat tergantung tingkat pelanggaran yang dilakukan anggota. PLC melakukan tinjauan keaktifan anggota selama tiga bulan sekali, hal tersebut dilakukan dengan salah satu cara yaitu razia dijalanan. Hal tersebut dilakukan agar sticker PLC tidak disalahgunakan. Keputusan ini juga dibuat bersama-sama untuk menjaga stabilitas komunitas. Menurut Emile Durkheim Solidaritas mekanis adalah solidaritas yang dibentuk dari hukum represif karena anggota masyarakat tersebut memiliki persamaan dan sangat cenderung percaya kepada moralitas bersama. (Ritzer George, 2012). Setiap pelanggaran pada sistem bersama tidak dianggap main-main oleh setiap individu. Bagi yang melanggar moral kolektif maka akan dihukum. Walau hanya merupakan pelanggaran kecil tetapi bisa saja akan di hukum berat. Sama halnya dengan komunitas PLC Kota Payakumbuh, apapun aturan yang telah dibuat sesuai keputusan bersama yang didapat dari hasil musyawarah harus ditaati dan jika ada anggota yang melanggar maka akan diberi sanksi mulai dari sanksi ringan hingga sanksi berat.

\section{Kesimpulan}

Dari hasil penelitian ini, peneliti menemukan ada 3 (tiga) nilai-nilai solidaritas sosial yang ditanamkan didalam PLC Kota Payakumbuh yaitu (1) nilai kekeluargaan yang bukan hanya dirasakan antar anggota saja melainkan seluruh keluarga anggota yang bergabung dalam PLC. Menyelesaikan konflik atau masalah secara baik-baik dengan kata lain secara kekeluargaan. (2) seluruh anggota PLC akan senantiasa saling membantu bahkan tidak hanya antar anggota melainkan juga kepada masyarakat lainnya. Seperti membantu anggota yang mengalami musibah kecelakaan atau trouble pada kendaraannya dijalanan dan atau membantu korban bencana. (3) setiap hal seperti membuat aturan, mencari solusi dari setiap masalah yang terjadi di dalam PLC seluruh anggota akan melakukan musyawarah untuk mendapatkan kesepakatan bersama demi kepentingan bersama. Bagi yang melanggar aturan yang telah dibuat sesuai kesepakatan bersama maka tidak main-main akan diberi sanksi mulai dari sanksi ringan hingga sanksi berat. Dari

\section{Culture \& Society: Journal of Anthropological Research Vol. 1, No. 1, Th. 2019}


Ririn Alwani, Erianjoni Erianjoni

penuturan di atas dapat dilihat bahwa nilai-nilai solidaritas yang ditanamkan di dalam komunitas PLC cukup tinggi. Sehingga nilai kekeluargaan di dalam komunitas sangat terasa, dan setiap anggota merasa memiliki rasa tanggung jawab untuk saling menolong dan membantu antar anggota dan antar sesama, serta terbiasa mendiskusikan dan memusyawarahkan hal-hal yang dirasa merupakan kepentingan bersama agar didapatkan keputusan bersama pada akhirnya.

\section{Daftar Pustaka}

Abdullah, S. (2013). Potensi dan Kekuatan Modal Sosial dalam Suatu Komunitas. SOCIUS : Jurnal Sosiologi.

Bungin, B. (2001). Metode Penelitian Kualitatif. Jakarta: PT Raja Grafindo.

Bungin, B. (2003). Analisis Data Penelitian Kualitatif. Jakarta: PT Raja Grafindo.

Bungin, B. (2007). Penelitian Kualitatif: Komunikasi, Ekonomi, Kebijakan Publik, dan Ilmu Sosial Lainnya. Jakarta: Kencana Prenada Media.

Dicky, S. F. (2016). Solidaritas Sosial Anggota Komunitas Motor Honda Classic Magelang (HCM) "Cub Series." IOSR Journal of Economics and Finance, 3(1), 56. https://doi.org/https://doi.org/10.3929/ethz-b-000238666

Dilema, J. S. (2017). Hubungan Antara Dukungan Kelompok Sosial Dengan Perilaku Pemilih Pada Pemilihan Kepala Daerah Kabupaten Sukoharjo Tahun 2015. 32(1), 1-8.

Iis Durotus. (2016). Solidaritas Sosial Masyarakat Kuningan di Yogyakarta (Studi Kasus Komunitas Paguyuban Pengusaha Warga Kuningan).

Maleong, J. L. (1998). Metodologi Penelitian Kualitatif. Jakarta: Rosda Karya.

Ritzer George. (2012). Teori Sosiologi (Dari Teori Sosiologi Klasik Sampai Perkembangan Terakhir Teori Sosial Postmodern). Yogyakarta: Pustaka Pelajar.

Rolitia, M., Achdiani, Y., \& Eridiana, W. (2016). Nilai Gotong Royong Untuk Memperkuat Solidaritas Dalam Kehidupan Masyarakat Kampung Naga. Sosietas. https://doi.org/10.17509/sosietas.v6i1.2871

Septiani Tessi. (2017). Internalisasi Nilai-nilai Sosial dalam Komunitas Pecinta Alam Aru-Aru Minang Adventure (KPAAMA) di Nagari Kasang Kecamatan Batang Anai Kabupaten Padang Pariaman. Skripsi Jurusan Sosiologi Fakultas Ilmu Sosial Universitas Negeri Padang. Retrieved from http://repository.unp.ac.id

Siwi Mahmudi. (n.d.). Konsep Komunitas dan Masyarakat dalam Perspektif dalam Perspektif Sosiologi. Jurnal. Retrieved from http://skpm.ipb.ac.id/konsep-komunitas-danmasyarakat-dalam-perspektif-sosiologi

Soekanto Soerjono. (1982). Sosiologi Sebagai Pengantar. Jakarta: Rajawali Pers.

Sugiyono. (2005). Memahami Penelitian Kualitatif. Bandung: CV. Alfabet.

Utami, F. N. H., \& Silalahi, B. Y. (2013). Hubungan antara identitas sosial dan konformitas pada anggota komunitas virtual kaskus regional Depok. Jurnal Psikologi.

W. John, C. (2010). Research Design Pendekatan Metode Kualitatif, Kuantitatif dan Campuran. Yogyakarta: Pustaka Pelajar. 